\title{
Thoracoscopic and endoscopic cooperative surgery (TECS): a novel less invasive technique for resection of gastric tube cancer after esophagectomy
}

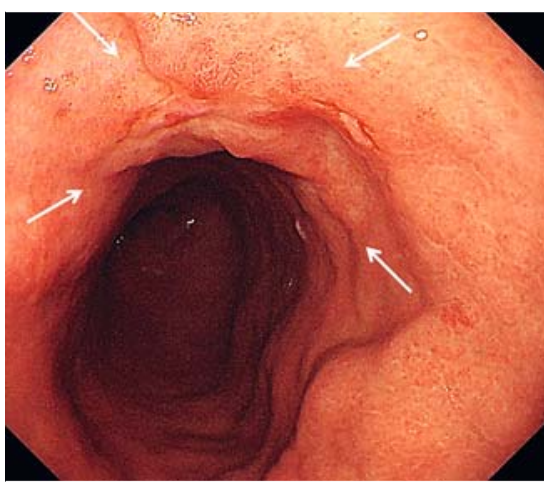

- Fig. 1 Endoscopic view of a depressed lesion (arrows) with an irregular surface observed in Patient \#1.

With recent improvements in the survival of patients after esophagectomy, the occurrence of secondary malignancies arising in the gastric tube has been increasing [1,2]. However, resection of the reconstructed gastric tube with lymphadenectomy for gastric tube cancer (GTC) is an invasive procedure associated with high morbidity and mortality [3]. Local resection without lymphadenectomy may be reasonable in high risk patients. We have developed a novel thoracoscopic and endoscopic cooperative surgery (TECS) technique as a minimally invasive alternative.

Two patients underwent TECS for GTC after esophagectomy. Patient \#1 had a $25 \mathrm{~mm}$, undifferentiated, submucosal invasive adenocarcinoma ( $\triangleright$ Fig. 1 ,

- Fig.2), which was considered difficult to resect completely by endoscopic submucosal dissection (ESD). Patient \#2 had undergone ESD for a $10 \mathrm{~mm}$ depressed GTC (> Fig.3); however, histopathological analysis revealed noncurative resection because of submucosal invasion to $1150 \mu \mathrm{m}$, with a positive vertical margin. The absence of metastasis was confirmed preoperatively using computed tomography. The TECS steps ( $\triangleright$ Video 1 ) were: 1) exposure of the gastric tube by
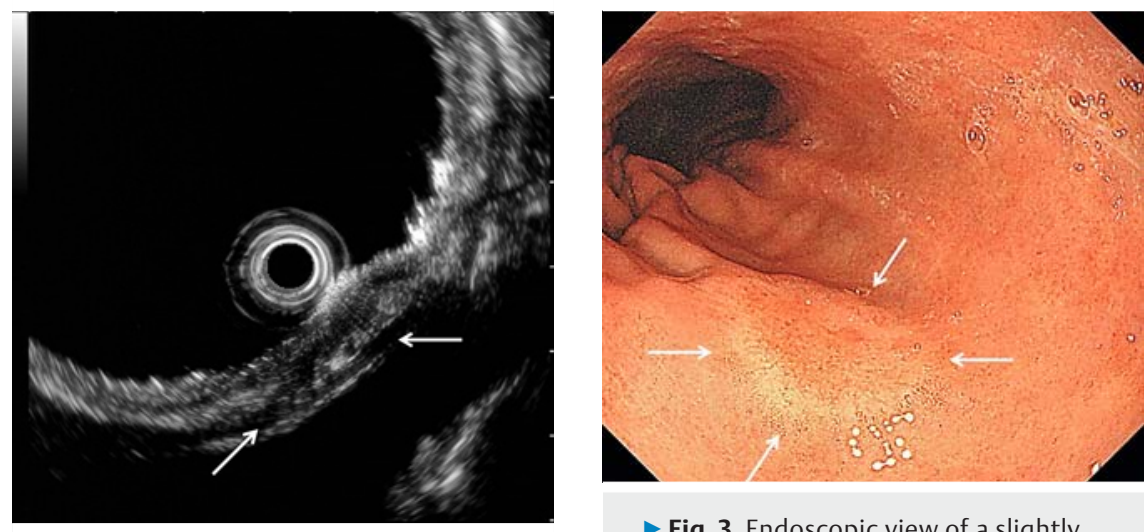

- Fig. 2 Endoscopic ultrasonographic image of a low-echoic tumor with deep invasion of the submucosal layer (arrows).
- Fig. 3 Endoscopic view of a slightly depressed lesion (arrows) observed in Patient \#2.

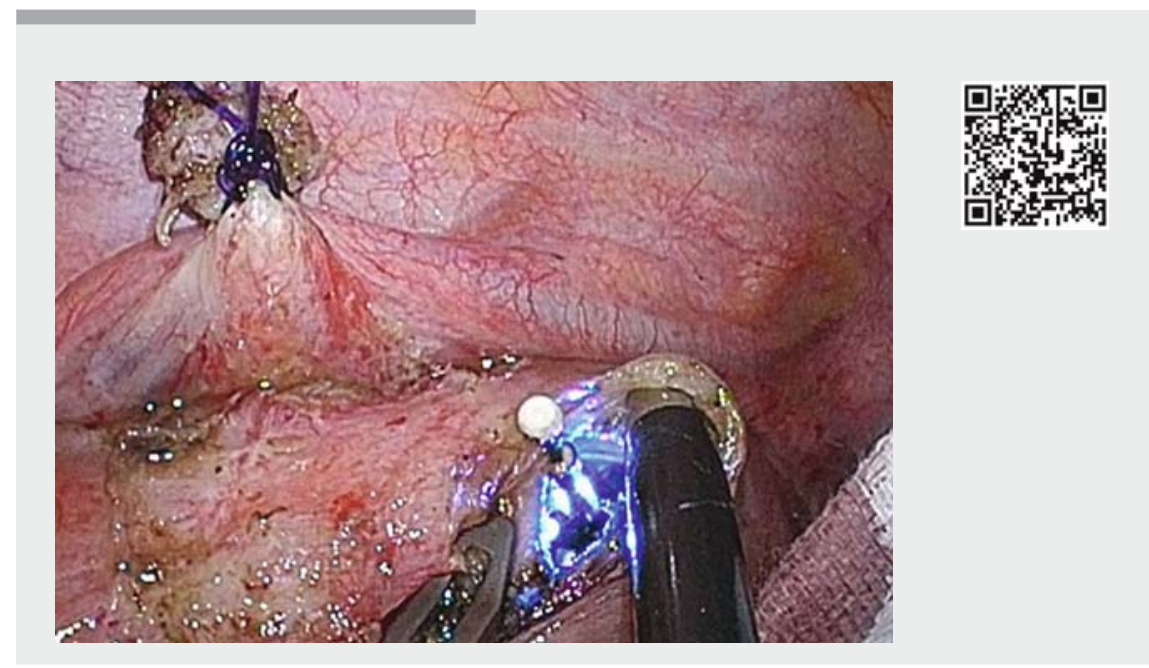

Video 1 Thoracoscopic and endoscopic cooperative surgery procedure in Patient \#2 with gastric tube cancer after noncurative endoscopic submucosal dissection.

thoracoscopy; 2) mucosal incision around the involved site and submucosal trimming using ESD technique, followed by full-thickness incision by endoscopy (ITknife 2; Olympus, Tokyo, Japan); 3) thoracoscopic resection with Harmonic scalpel (Ethicon, Somerville, New Jersey, USA); 4) suturing.

Both TECS procedures were performed under general anesthesia with orotra- cheal intubation and were successfully completed in 250 and 420 minutes, respectively. Blood loss was minimal. No perioperative complications such as anastomotic leaks, bleeding, or stricture were observed. Oral intake was started on postoperative days 7 and 8 . The patients were discharged 14 and 25 days after the procedure. 
ESD for GTC is sometimes technically difficult with fibrosis [4], and the long-term outcomes for noncurative patients are reportedly less satisfactory [5]. Although careful follow-up for possible metastasis is necessary in our patients, TECS was a feasible, safer, and less invasive therapeutic option for patients with noncurative GTC.

Endoscopy_UCTN_Code_TTT_1AT_2AF

Competing interests

None

The authors

Yoshiki Tsujiii ${ }^{1}$, Makoto Yamasaki ${ }^{2}$, Yoshito Hayashi $^{1}$, Koji Tanaka ${ }^{2}$, Tomoki Makino ${ }^{2}$, Yuichiro Doki ${ }^{2}$, Tetsuo Takehara ${ }^{1}$

1 Department of Gastroenterology and Hepatology, Osaka University Graduate School of Medicine, Suita, Japan

2 Department of Gastroenterological Surgery, Osaka University Graduate School of Medicine, Suita, Japan
Corresponding author

\section{Tetsuo Takehara, MD, PhD}

Department of Gastroenterology and Hepatology, Osaka University Graduate School of Medicine, 2-2 Yamadaoka, Suita, Osaka 565-0871, Japan

Fax: +81-6-68793629

takehara@gh.med.osaka-u.ac.jp

\section{References}

[1] Matsubara T, Yamada K, Nakagawa A. Risk of second primary malignancy after esophagectomy for squamous cell carcinoma of the thoracic esophagus. J Clin Oncol 2003; 21: $4336-4341$

[2] Okamoto N, Ozawa S, Kitagawa Y et al. Metachronous gastric carcinoma from a gastric tube after radical surgery for esophageal carcinoma. Ann Thorac Surg 2004; 77: $1189-1192$

[3] Sugiura $T$, Kato $H$, Tachimori $Y$ et al. Second primary carcinoma in the gastric tube constructed as an esophageal substitute after esophagectomy. J Am Coll Surg 2002; 194: $578-583$

[4] Nishide N, Ono H, Kakushima N et al. Clinical outcomes of endoscopic submucosal dissection for early gastric cancer in remnant stomach or gastric tube. Endoscopy 2012; 44: $577-583$

[5] Nonaka S, Oda I, Sato C et al. Endoscopic submucosal dissection for gastric tube cancer after esophagectomy. Gastrointest Endosc 2014; 79: 260 - 270

\section{Bibliography}

DOI https://doi.org/10.1055/a-0751-2540

Published online: 7.11.2018

Endoscopy 2019; 51: E5-E6

(c) Georg Thieme Verlag KG

Stuttgart · New York

ISSN 0013-726X

\section{ENDOSCOPY E-VIDEOS}

https://eref.thieme.de/e-videos

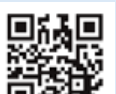

Endoscopy E-Videos is a free access online section, reporting on interesting cases and new

techniques in gastroenterological endoscopy. All papers include a high quality video and all contributions are freely accessible online.

This section has its own submission website at https://mc.manuscriptcentral.com/e-videos 